\title{
PRILAKU KONSUMEN DALAM PENGAMBILAN KEPUTUSAN PEMBELIAN APEL LOKAL PASURUAN TERHADAP PEMENUHAN KEPUASAN KONSUMEN
}

\author{
Wenny Mamilianti* \\ *Dosen Fakultas Pertanian Universitas Yudharta Pasuruan \\ Imail: mamiliantiw@yahoo.co.id
}

\begin{abstract}
ABSTRAK
Konsumen merupakan hal yang sangat penting dalam hal mempertahankan komoditi yang di pasrkan oleh pemasar, pemasaran yang baik selalu memperhatikan produk yang dipasarkan agar dapat memuaskan konsumen terutama terutama pemasaran komoditi buah apel. Hal yang paling serius untuk diperhatikan adalah tetap mempertahankan kualitas, rasa, dan melakukan pasca panen dengan baik agar produk bertahan lama. Tujuan penelitian untuk mengetahui faktor yang mempengaruhi kepuasan konsumen. Dalam pengambilan data kuisoner sampel konsumen berjumlah 30 responden. Metode pengumpulan data yaitu meliputi data primer yaitu : observasi, wawancara, kuisoner dan dokumentasi. Sedangkan data skunder yaitu profil Kecamatan, Informasi dan arsip. Dalam sekala perhitungan kuisoner yaitu variabel bebas yaitu harga, kualitas, rasa dan desain. Sedangkan variabel terikat adalah variabel yang mempengaruhi kepuasan konsumen dengan menggunakan analisis uji validitas dan reliabilitas Hasil dari uji validitas dan reliabilitas menunjukan bahwa harga berpengaruh tergadap kepuasan konsumen dengan nilai korelasi 0.367 , variabel kualitas 0.440 , variabel rasa 0.419 , variabel desain 0.423 . Diantara variabel yang memiliki pengaruh yang paling nyata adLah variabel Kualitas, maka kesimpulan yang dapat didapat dari hipotesis adalah adanya pengaruh nyata antara variabel kualitas terhadap kepuasan konsumen apel nongkojajar.
\end{abstract}

Kata Kunci : konsumen , Kepuasan Konsumen, Apel Pasuruan

\section{PENDAHULUAN}

\section{LATAR BELAKANG}

Suatu produk akan memberikan manfaat kepada konsumen jika produk tersedia telah digunakan atau di konsumsi. Agar produk bisa memberikan manfaat maksimal dan kepuasan tinggi maka konsumen harus dapat mengunakan atau mengkonsumsi suatu produk dengan benar. Hal itu berlaku juga untuk produk olahan maupun produk hasil budidaya tanaman misalnya buah apel dan lain-lain.

Suatu produk yang mampu bersaing dalam pasar adalah yang memuaskan konsumen. Menurut kotler
(2001) menyatakan bahwa kepuasan konsumen adalah tingkat perasaan seseorang setelah membandingkan kinerja (atau hasil) yang ia rasakan dibandingkan dengan harapannya. Bila kinerja melebihi harapan mereka akan merasa puas dan sebaliknya apabila kinerja tidak sesuai harapan maka akan kecewa. Dengan kualitas produk yang baik akan menciptakan kepuasan bagi para konsumen, konsumen akan merasa puas ketika produk yang dibeli berkualitas baik. Apabila konsumen benar-benar merasa puas mereka akan membeli ulang serta 
memberi rekomendasi kepada orang lain untuk membeli produk yang sama.

Selain kualitas produk yang baik, kepuasan konsumen juga dipengaruhi oleh harga. Harga apel produksi dalam negeri lebih mahal dari buah apel dari luar negeri, dengan harga yang lebih tinggi mempengaruhi tingkat kepuasaan konsumen terhadap apel. Pada dasarnya konsumen dalam menilai suatu harga tidak tergantung hanya dari nilai nominal harga saja namun apakah dengan harga yang ditawarkan sudah sesuai dengan kualitas produk yang kita inginkan.

Seiring berkembangnya zaman ini yang semakin modern desain produk menjadi alat yang vital dalam hal kepuasan konsumen. Ada beberapa produsen apel dalam negeri yang sudah memperhatikan masalah desain produk, mereka menggunakn teknologi dalam penanganan pasca panen buah apel dengan tujuan agar dapat meningkatkan pendapatan dan memuaskan permintaan kosumen.

Konsistensi rasa suatu produk memberikan pengaruh yang cukup besar terhadap kepuasan konsumen karena berperan penting dalam menjaga konsumen agar tidak pindah ke produk lain. Apel produksi dalam negeri terkenal dengan cita rasa yang sangat manis untuk tipe buah apel manalagi dan masam untuk tipe buah apel ana. Banyak konsumen yang bertahan membeli buah apel produksi dalam negeri maupun perusahaan yang mencari apel produksi dalam negeri sebagai bahan baku pembuatan sari buah

Kecamatan Tutur Kabupaten Pasuruan adalah merupakan salah satu daerah penghasil buah apel atau di sebut dengan apel Nongkojajar. Jenis apel nongkojajar bermacam-macam antara lain apel Manalagi, apel Anna, dll. Di pasar dalam negeri apel Nongkojajar mempunyai pesaing dari segi harga dan kualitas yaitu apel yang berasal dari kota Batu atau biasanya disebut apel batu. Harga apel Batu bersaing dengan apel Nongkojajar, dari segi kualitas apel Batu sedikit mempunyai keunggulan karena hampir semua menggunakan teknologi dalam penanganan apel yaitu pengepakan apel segar sudah mengunakan mesin modern di bandingkan dengan penanganan apel Nongkojajar yang hanya sebagaian saja menggunakan teknologi. Rasa apel Nongkojajar lebih enak dibandingkan dengan apel Batu karena budidaya apel nongkojajar rata-rata menggunakan teknik budidaya yang semi-organik, petani ingin menjaga cita rasa dari apel nongkojajar dengan tidak menggunakan terlalu banyak bahan kimia. Kemasan/desain produk apel nongkojajar bisa dikatakan baik karena ada beberapa petani/produsen dalam penanganan pasca panen sudah menggunakan teknologi mulai dari sortasi sampai packing. Berdasarkan uraian latar 
belakang di atas, perlu dilakukan penelitian lebih lanjut masalah "Analisis Faktor-Faktor Yang Mempengaruhi Kepuasan Konsumen Terhadap Apel Nongkojajar Pasuruan" untuk mendapatkan informasi tentang sejauh mana kepuasan konsumen terhadap apel .

\section{TUJUAN PENELITIAN}

Tujuan dari penelitian ini adalah :

1. Untuk mengetahui faktor-faktor yang mempengaruhi kepuasan konsumen terhadap buah apel Nongkojajar

2. Untuk mengetahui faktor manakah yang memberikan pengaruh nyata terhadap kepuasan konsumen.

\section{METODE PENELITIAN}

Penelitian ini dilakukan di Kecamatan Tutur Kabupaten Pasuruan. Pengambilan dan penentuan lokasi penelitian ini dilakukan secara purposive (sengaja) dimana penentuan ini dikarenakan bahwa daerah tersebut merupakan tempat penghasil buah apel. Penelitian ini dilakukan pada bulan mei sampai juni 2014.

\section{Teknik Analis Data}

Analisis data yang digunakan dalam penelitian ini adalah analisis regresi sederhana, dan untuk menguji hipotesis statistik dilakukan uji ketetapan model, dan uji signifikasi model. Untuk mempermudah dalam menganalisis data peneliti mengunakan microsoft excel sebagai tabulasi data yang didapat dari kuesioner.

\section{Uji Validitas dan Uji Reliabilitas pada instrumen}

\section{Uji Validitas}

Uji validitas dilakukan pada setiap item, sehingga nantinya dapat disimpulkan bahwa semua kuisioner tersebut reliable dan dapat digunakan sebagai suatu instrument untuk dapat mengumpulkan data dari responden dengan jumlah yang lebih besar. Pengujian validitas ini diperoleh dengan cara membandingkan korelasi antara setiap skor indikator dengan total skor indikator variabel, dan kemudian dari hasil korelasi dibandingkan dengan nilai kritis pada taraf signifikan 0,05 (5\%). Jadi apabila $\boldsymbol{p}$ value atau nilai signifikan kurang dari 0,05 (55) maka dinyatakan valid dan sebaiknya jika nilai $\boldsymbol{p}$ value atau signifikan lebih dari 0,05 (5\%) dinyatakan tidak valid. Sedangkan rumus yang digunakan untuk mengukur validitas instrumen dalam penelitian ini adalah Product moment dari person sebagai berikut

$$
\sqrt{\mathrm{Rxy}=} \frac{n \sum X Y-\left(\sum X\right)\left(\sum Y\right)}{\sqrt{\left\{n \sum_{X} 2-\left(\sum_{X} 2\right)\right\}\left\{n \sum_{y} 2-\left(\sum_{y} 2\right)\right\}}}
$$

Dimana :

$r=$ koefesien korelasi variabel bebas dan variabel terikat

$\mathrm{n}=$ banyaknya sampel 
$\mathrm{x}=$ skor setiap item

$\mathrm{y}=$ skor total variabel

\section{Uji Reliabilitas}

Reliabilitas adalah konsistensi alat pengumpul data/ instrumen dalam mengukur apa saja yang diukur. Instrumen yang reliable maksunya instrumen yang jika digunakan beberapa kali untuk mengukur obyek yang sama, maka akan tetap menghasilkan data yang sama. Realiabiliti instrumen merupakamn syarat untuk pengujian validitas instrumen. Oleh karena itu, walau instrumen yang valid umumnya pastireliable, tetapi penguji reliabilitas instrumen perlu dulakukan untuk menambah keakuratan data (Sugiyono, 2012). Informasi tersebut bisa didapat baik secara langsung(data primer) maupun tidak langsung (data sekunder, tersier, dsb). Hasil penelitian dikatakan reliabilitas jika terdapat kesamaan data pada waktu yang berbeda. Dengan menggunakan instrumen yang valid dan reliable dalam pengumpulan data, maka diharapkan hasil penelitian akan menjadi valid dan reliabel. Jadi instrumen yang valid dan reliadle merupakan syarat mutlak untuk mendapatkan hasil penelitian yang valid dan reliabel (Sugiyono, 2012).

Tingkat reliabilitas suatu kontruk atau variabel penelitian dapat dilihat dari hasil statistik Cronbach Alpha () suatu variabel dikatakan reliabel jika memberikan nilai Cronbach Alpha >0,06
(Ghozali, 2005dalam indriaty, 2010). Semakin nilai alphanya mendekati 1 maka nilai reliabilitas reliabilitas datanya semakin terpecaya. Adapun rumus

\section{Cronbach Alpha}

$$
\mathbf{r} 11=\left\lfloor\frac{k}{k-1}\right\rfloor\left[1-\frac{\sum a b^{2}}{\pi^{2}}\right]
$$

Dimana

r11 = Reliabilitas instrumen

$\mathrm{k} \quad=$ Banyaknya butir pertanyaan atau banyaknya soal

$\sum a b^{2}=$ Jumlah variabel butir

$\pi^{2} \quad=$ Jumlah variabel Total

Setelah dilakukan perhitungan kemudian dibandingkan dengan tabel nilai kritisnya dengan ketentuan sebagai berikut:

○ Jika $r$ hitung positif dari $r$ hitung $>t$ tabel maka variabel tersebut reliabel

- Jika $r$ hitung positif dari $r$ hitung $>t$ tabel maka variabel tersebut tidak reliabel

Hal ini tidak berarti bahwa dengan mengunakan instrumen yang telah teruji validitas dan reliabilitasnya, otomayis hasil (data) penelitian menjadi valid dan reliabel. Karena hal tersebut masih di pengaruhi oleh kondisi obyek yang diteliti dan kemampuan orang yang mengunakan instrumen untuk mengumpulkan data. Oleh karena itu, penelitian harus mampu mengendalikan dan mengunakan instrumen untuk mengukur variabel yang diteliti. Reliabilitas instrumen merupakan 
syarat untuk pengujian validitas instrumen.

Oleh karena itu, walaupun instrumen yang valid umumnya pasti reliable, tetapi penguji reliabilitas instrumen perlu dilakukan, untuk menambah keakuratan data (Sugiyono, 2012). Selain itu kreteria lain instrumen yang baik adalah kekuatan penelitian bisa diketahui dari validitas baik internal maupun eksternal.

Validitas internal dalah keyakinan terhadap hubungan sebab akibat atau pengaruh dalam desain penelitian yang dilakukan. Validitas eksternal adalah berkenaan dengan kemampuan digeneralisasinya hasil penelitian pada lingkungan, orang, atau peristiwa lain. Ancaman yang mempengaruhi validitas internal adalah history effects, maturity effects, testing effects, instrumentation effects, selection effects, statistical regression, dan mortality. Ancaman yang mempengaruhi validitas eksternal adalah perbedaab situasi lingkungan peneliti, dan perbedaan subyek penelitian.
Metode Mengukur Tingkat Kepuasan Konsumen

Menurut Kotler (1997:38) metode yang digunakan oleh perusahaan untuk mengetahui tingkat kepuasan konsumen yaitu Survei kepuasan konsumen. Survei kepuasan konsumen dapat dilakukan dengan cara survei melalui pos surat, telephone, maupun wawancara pribadi. Dengan metode ini perusahaan dapat menciptakan komunikasi 2 arah dan menunjukan perhatiannya kepada konsumen.

\section{HASIL DAN PEMBAHASAN}

\section{Uji Validitas dan Reabilitas Harga}

Hasil uji validitas dan reabilitas dalam penelitian ini adalah dengan menggunakan rumus Cronbach's Alpha, instrumen penelitian yang didasarkan pada jawaban 30 responden menyatakan bahwa instrumen penelitian pada variabel Harga adalah sesuai dengan uji validitas dan reabilitas serta dapat digunakan untuk mengukur dalam rangka untuk mengumpulkan data selanjutnya. Adapun hasil pengujiannya dapat dilihat pada tabel berikut: 
Tabel 1. Analisis Validitas dan Reabilitas Harga

\begin{tabular}{|l|l|l|l|l|}
\hline Variabel & Item & \multicolumn{2}{|l|}{ Validitas } & \multirow{2}{*}{$\begin{array}{l}\text { Cronbach's } \\
\text { Alpha }\end{array}$} \\
\cline { 3 - 4 } & & Korelasi (r) & Probabilitas (p) & \\
\hline \multirow{3}{*}{ Harga } & $\mathrm{X} 1.1$ & 0.661 & 0.000 & \\
\cline { 2 - 4 }$(\mathrm{X} 1)$ & $\mathrm{X} 1.2$ & 0.638 & 0.000 & \multirow{3}{*}{0.735} \\
\cline { 2 - 4 } & $\mathrm{X} 1.3$ & 0.673 & 0.000 & \\
\cline { 2 - 4 } & $\mathrm{X} 1.4$ & 0.698 & 0.000 & \\
\cline { 2 - 4 } & $\mathrm{X} 1.5$ & 0.398 & 0.000 & \\
\hline
\end{tabular}

Sumber: Data Primer (Diolah)

Pengujian validitas dan Reliabilitas pada instrumen variabel Harga (X1) diperoleh bahwa hasil instrumen penelitian yang digunakan berdasarkan tabel 5.5 yang menunjukan bahwa semua variabel pertanyaan mempunyai indeks korelasi lebih besar dari 0.3 dan indeks cronbach's alpha sebesar 0.735 yang berarti sangat reabel sesuai dengan ketentuan reliabelitas nilai alpha, dengan demikian berarti bahwa pertanyaan untuk variabel Harga (X1) memiliki kesesuaian dengan ketentuan uji validitas dan reliabilitas sehingga penelitian dapat melanjutkan untuk melakukan tahap uji analisis selanjutnya.

Dari hasil analisis menjelaskan bahwa harga memiliki pengaruh yang nyata terhadap kepuasan konsumen apel nongkojajar. Hal ini berarti bahwa konsumen akan memilih apel nongkojajar dengan harga yang relatif rendah. Dalam penelitian ini konsumen yang menilai bahwa apel nongkojajar memiliki harga yang terjangkau dan berada pada harga yang bersaing mereka cenderung memiliki kepuasan lebih tinggi terhadap apel nongkojajar. Pada saat transaksi atau kunjungan calon konsumen, konsumen akan membandingkan harga apel nongkojajar dengan apel lain yang ada, dan jika mendapatkan bahwa apel nongkojajar tersebut dapat memberikan kesesuaian dengan dana yang dikehendaki konsumen maka kepuasan konsumen akan terjadi.

Berdasarkan data responden tengkulak apel di wilayah Nongkojajar kisaran harga apel manalagi adalah Grade A super $=$ Rp. $12.000 / \mathrm{kg}$, Grade A $=$ Rp. $11.000 / \mathrm{kg}$, Grade AB = Rp. $10.000 / \mathrm{kg}$, Grade B = Rp. 8.000/kg, Grade C = Rp. 6.000/kg, Grade D = Rp. 4.000/kg dan harga tingkat petani borongan Rp. 15.000.

Bardasarkan data responden kisaran umur 10-20 tahun, berjenis kelamin perempuan adalah sebanyak 23 orang, pada tingkat pendidikan SD-SMP yang berjumlah 9 orang dan pada tingkat pekerjaan serabutan - ibu rumah tangga yang berjumlah 10 orang semua 
menyatakan bahwa harga mempengaruhi terhadap kepuasan konsumen.

Hal ini sesuai dengan teori pendukung menurut penelitian Akhsay R. Rao dan Kent B. Monroe (1989) dal (Suwendra Kumar, 2005). Menyatakan bahwa konsumen mempunyai anggapan adanya hubungan yang positifantara harga dan kepuasan suatu produk, maka mereka akan membandingkan antara produk yang satu dengan produk yang lainnya dan barulah konsumen mengalmbil kepuasan untuk produk tersebut.

Dengan demikian sesuai dengan hipotesis yang menyatakan bahwa harga berpengaruh terhadapkepuasan konsumen.
Sehingga penelitian ini telah diperkuat penelitian yang dilakukan sebelumnya.

\section{Analisis Validitas dan Reabilitas Kualitas}

Hasil uji validitas dan reabilitas dalam penelitian ini adalah dengan menggunakan rumus Cronbach's Alpha, instrumen penelitian yang didasarkan pada jawaban 30 responden menyatakan bahwa instrumen penelitian pada variabel Kualitas adalah sesuai dengan uji validitas dan reabilitas serta dapat digunakan untuk mengukur dalam rangka untuk mengumpulkan data selanjutnya. Adapun hasil pengujiannya dapat dilihat pada tabel berikut:

Tabel 2. Analisis Validitas dan Reabilitas Kualitas

\begin{tabular}{|c|c|c|c|c|}
\hline \multirow{3}{*}{ Variabel } & \multirow{2}{*}{ Item } & \multicolumn{2}{|c|}{ Validitas } & Cronbach's \\
& & Korelasi (r) & Probabilitas (p) & Alpha \\
\cline { 3 - 4 } & & 0.863 & 0.000 & \\
\cline { 2 - 4 } Kualitas & $\mathrm{X} 2.1$ & 0.834 & 0.000 & \multirow{2}{*}{0.910} \\
\cline { 2 - 4 } & $\mathrm{X} 2.2$ & 0.850 & 0.000 & \\
\cline { 2 - 4 } & $\mathrm{X} 2.3$ & 0.861 & 0.000 & \\
\cline { 2 - 4 } & $\mathrm{X} 2.4$ & 0.628 & 0.000 & \\
\hline
\end{tabular}

Sumber: Data Primer (Diolah)

Pengujian validitas dan Reliabilitas pada instrumen variabel Kualitas (X2) diperoleh bahwa hasil instrumen penelitian yang digunakan berdasarkan tabel 5.6 yang menunjukan bahwa semua variabel pertanyaan mempunyai indeks korelasi lebih besar dari 0.3 dan indeks cronbach's alpha sebesar 0.910 yang berarti sangat reabel sesuai dengan ketentuan reliabelitas nilai alpha, dengan demikian berarti bahwa pertanyaan untuk variabel Kualitas (X2) memiliki kesesuaian dengan ketentuan uji validitas dan reliabilitas sehingga penelitian dapat melanjutkan untuk melakukan tahap uji analisis selanjutnya.

Dari hasil analisis menjelaskan bahwa kualitas memiliki pengaruh yang nyata terhadap kepuasan konsumen apel 
nongkojajar. Hal ini menjelaskan bahwa pengalaman konsumen dalam mengkonsumsi apel nongkojajar akan menghasikan penilaian konsumen terhadap produk tersebuut. Dengan penilaian tersebut maka kondumen akan tetap berkeinginan untuk membeli apel nongkojajar. Hasil ini menjelaskan bahwa pada umumnya konsumen dalam membelanjakan uanya akan memperhitungkan kualitas yang dapat diperoleh dari uang yang kan dikeluarkannya.

Berdasarkan data responden pada rentang usia 21-54 tahun berjuklah 20 orang, responden yang berjenis kelamin perempuan adalah sebanyak 23 orang, pada tingkat pendidikan SLTA-PT yang berjumlah 21 orang dan Pada tingkat pekerjaan karyawan swasta - dan lain lain yang berjumlah 20 orang mereka semua nyatakan bahwa kualitas berpengaruh terhadap kepuasan konsumen. Penjelasan diatas didukung dengan teori lupiyoadi (2001:158) menyatahkan bahwa “ konsumen akan merasa puas bila hasil evaluasi meraka menunjukan bahwa produk yang mereka gunakan berkualitas". Maka sesuai dengan hipotesis yang menyatakan bahwa kualitas berpengaruh terhadap kepuasan konsumen. Sehingga penelitian ini telah memperkuat penelitian yang dilakukan sebelumnya.

\section{Analisis Validitas dan Reabilitas Rasa}

Hasil uji validitas dan reabilitas dalam penelitian ini adalah dengan menggunakan rumus Cronbach's Alpha, instrumen penelitian yang didasarkan pada jawaban 30 responden menyatakan bahwa instrumen penelitian pada variabel Rasa adalah sesuai dengan uji validitas dan reabilitas serta dapat digunakan untuk mengukur dalam rangka untuk mengumpulkan data selanjutnya. Adapun hasil pengujiannya dapat dilihat pada tabel berikut:

Tabel 4. Validitas dan Reabilitas Rasa

\begin{tabular}{|c|c|c|c|c|}
\hline Variabel & \multirow{2}{*}{ Item } & \multicolumn{2}{|c|}{ Validitas } & Cronbach's \\
& & Korelasi (r) & Probabilitas (p) & Alpha \\
\hline \multirow{3}{*}{ Rasa } & $\mathrm{X} 3.1$ & 0.886 & 0.000 & \\
\cline { 2 - 4 } & $\mathrm{X} 3.2$ & 0.810 & 0.000 & \multirow{2}{*}{0.832} \\
\cline { 2 - 4 }$(\mathrm{X} 3)$ & $\mathrm{X} 3.3$ & 0.783 & 0.000 & \\
\cline { 2 - 4 } & $\mathrm{X} 3.4$ & 0.658 & 0.000 & \\
\cline { 2 - 4 } & $\mathrm{X} 3.5$ & 0.395 & 0.000 & \\
\hline
\end{tabular}

Sumber: Data Primer (Diolah)

Pengujian validitas dan reliabilitas

pada instrumen variabel Rasa (X3) diperoleh bahwa hasil instrumen penelitian yang digunakan berdasarkan tabel 5.7 yang 
menunjukan bahwa semua variabel pertanyaan mempunyai indeks korelasi lebih besar dari 0.3 dan indeks cronbach's alpha sebesar 0.832 yang berarti sangat reabel sesuai dengan ketentuan reliabelitas nilai alpha, dengan demikian berarti bahwa pertanyaan untuk variabel Rasa (X3) memiliki kesesuaian dengan ketentuan uji validitas dan reliabilitas sehingga penelitian dapat melanjutkan untuk melakukan tahap uji analisis selanjutnya. Dari hasil analisis menjelaskan bahwa rasa memiliki pengaruh yang nyata terhadap kepuasan konsumen. Salah satu study menyebutkan bahwa rasa adalah hal yang sangat penting karena menyangkut produk dan kualitas tersebut (Nurul ,2009). Teori lai menyebutkan bahwa rasa adalah emosi dasar orang (Watson,1996).

Berdasarkan data responden pada rentang usia 21-54 tahun berjuklah 20 orang, responden yang berjenis kelamin perempuan adalah sebanyak 23 orang, pada tingkat pendidikan SLTA-PT yang berjumlah 21 orang dan Pada tingkat pekerjaan karyawan swasta - dan lain lain yang berjumlah 20 orang mereka semua nyatakan bahwa rasa berpengaruh terhadap kepuasan konsumen. Dari hal diats dapat disimpulkan bahwa rasa merupakan salah satu elemen dari faktor-faktor deferensiasi yang dapat mempengaruhi kepuasan konsumen karena ada perangkat emosi yang mendasar pada setiap individu. Dalam penelitian ini bahwa terbukti hipotesis yang menyatakan rasa mempunyai pengaruh terhadap kepuasan pembeli.

\section{Analisis Validitas dan Reabilitas Desain}

Hasil uji validitas dan reabilitas dalam penelitian ini adalah dengan menggunakan rumus Cronbach's Alpha, instrumen penelitian yang didasarkan pada jawaban 30 responden menyatakan bahwa instrumen penelitian pada variabel Desain adalah sesuai dengan uji validitas dan reabilitas serta dapat digunakan untuk mengukur dalam rangka untuk mengumpulkan data selanjutnya. Adapun hasil pengujiannya dapat dilihat pada tabel berikut: 
Tabel 5. Analisis Validitas dan Reabilitas Desain

\begin{tabular}{|c|c|c|c|c|}
\hline \multirow{2}{*}{ Variabel } & \multirow{2}{*}{ Item } & \multicolumn{2}{|c|}{ Validitas } & Cronbach's \\
\cline { 3 - 4 } & & Korelasi (r) & Probabilitas (p) & Alpha \\
\hline \multirow{3}{*}{ Desain } & $\mathrm{X} 4.1$ & 0.824 & 0.000 & \\
\cline { 2 - 4 } & $\mathrm{X} 4.2$ & 0.845 & 0.000 & \multirow{2}{*}{0.892} \\
\cline { 2 - 4 }$(\mathrm{X} 4)$ & $\mathrm{X} 4.3$ & 0.715 & 0.000 & \\
\cline { 2 - 4 } & $\mathrm{X} 4.4$ & 0.810 & 0.000 & \\
\cline { 2 - 4 } & $\mathrm{X} 4.5$ & 0.715 & 0.000 & \\
\hline
\end{tabular}

Sumber: Data Primer (Diolah)

Pengujian validitas dan reliabilitas pada instrumen variabel Desain (X4) diperoleh bahwa hasil instrumen penelitian yang digunakan berdasarkan tabel 5.8 yang menunjukan bahwa semua variabel pertanyaan mempunyai indeks korelasi lebih besar dari 0.3 dan indeks cronbach's alpha sebesar 0.892 yang berarti sangat reabel sesuai dengan ketentuan reliabelitas nilai alpha, dengan demikian berarti bahwa pertanyaan untuk variabel Desain (X4) memiliki kesesuaian dengan ketentuan uji validitas dan reliabilitas sehingga penelitian dapat melanjutkan untuk melakukan tahap uji analisis selanjutnya.

Berdasarkan data responden pada rentang usia 21-54 tahun berjuklah 20 orang, responden yang berjenis kelamin perempuan adalah sebanyak 23 orang, pada tingkat pendidikan SLTA-PT yang berjumlah 21 orang dan Pada tingkat pekerjaan karyawan swasta - dan lain lain yang berjumlah 20 orang mereka semua nyatakan bahwa desain berpengaruh terhadap kepuasan konsumen.
Dari hasil analisis menjelaskan bahwa desain memiliki pengaruh yang nyata terhadap kepuasan konsumen. Penjelasan diatas didukung dengan teori Kotler dan Armstrong (2001:367) menyatakan bahwa fungsi primer kemasan adalah untuk memuat dan melindungi produk. Tapi seiring berkembangnya zaman ini kemasan menjadi alat yang vital dalam hal kepuasan konsumen. Maka sesuai dengan hipotesis yang menyatakan bahwa desain berpengaruh terhadap kepuasan konsumen. Sehingga penelitian ini telah memperkuat penelitian yang dilakukan sebelumnya.

\section{Analisis Validitas dan Reabilitas semua}

\section{Variabel}

Hasil uji validitas dan reabilitas dalam penelitian ini adalah dengan menggunakan rumus Cronbach's Alpha, instrumen penelitian yang didasarkan pada jawaban 30 responden menyatakan bahwa instrumen penelitian pada semua variabel adalah sesuai dengan uji validitas dan reabilitas serta dapat digunakan untuk 
mengukur dalam rangka untuk hasil pengujiannya dapat dilihat pada tabel mengumpulkan data selanjutnya. Adapun berikut:

Tabel 6 Uji Validitas dan Reabilitas semua Vaeriabel

\begin{tabular}{|c|c|c|c|c|}
\hline \multirow{2}{*}{$\begin{array}{l}\text { Variabel } \\
\text { Dependen }\end{array}$} & \multirow{2}{*}{$\begin{array}{c}\text { Variabel } \\
\text { Independen }\end{array}$} & \multicolumn{2}{|c|}{ Validitas } & \multirow{2}{*}{$\begin{array}{c}\text { Cronbach's } \\
\text { Alpha }\end{array}$} \\
\hline & & Korelasi (r) & Probabilitas $(\mathrm{p})$ & \\
\hline \multirow{4}{*}{ Puas } & Harga & 0.367 & 0.000 & \multirow{4}{*}{0.735} \\
\hline & Kualitas & 0.440 & 0.000 & \\
\hline & Rasa & 0.419 & 0.000 & \\
\hline & Desain & 0.423 & 0.000 & \\
\hline
\end{tabular}

Sumber: Data Primer (Diolah)

Pengujian validitas dan reliabilitas pada instrumen variabel dependen diperoleh bahwa hasil instrumen penelitian yang digunakan berdasarkan tabel 5.9 yang menunjukan bahwa semua variabel pertanyaan mempunyai indeks korelasi lebih besar dari 0.3 dan indeks cronbach's alpha sebesar 0.735 yang berarti sangat reabel sesuai dengan ketentuan reliabelitas nilai alpha, dengan demikian berarti bahwa pertanyaan untuk variabel dependen memiliki kesesuaian dengan ketentuan uji validitas dan reliabilitas sehingga penelitian dapat melanjutkan untuk melakukan tahap uji analisis selanjutnya.

Dari hal diatas dapat disimpulkan bahwa kualitas merupakan salah satu elemen dari faktor-faktor deferensiasi yang sangat nyata mempengaruhi terhadap kepuasan konsumen. Penjelasan diatas didukung dengan teori lupiyoadi (2001:158) menyatahkan bahwa “ konsumen akan merasa puas bila hasil evaluasi meraka menunjukan bahwa produk yang mereka gunakan berkualitas“. yang mendasar pada setiap individu. Dalam penelitian ini bahwa terbukti hipotesis harga $\mathrm{H}_{1}$ ditolak $\mathrm{H}_{0}$ diteirma yang menyatakan kualitas mempunyai pengaruh nyata terhadap kepuasan pembeli.

Ada beberapa faktor yang menyebabkan kualitas sangat beepengaruh nyata terhadap kepuasan konsumen antara lain:

1. Pendidikan 21 dari 30 responden adalah mulai tingkat SLTA - PT, sehingga pada tingkat pendidikan tinggi mereka lebih menekankan kualitas, mutu, dan manfaat ketika membeli buah apel.

2. Mereka tidak begitu memperhitungkan harga dalam hal membeli karena mereka lebih melihat apakah buah apel yang di beli sesuai dengan kualitas yang diinginkan.

3. Dengan mutu kualitas yang baik mereka berani membayar berapapun harganya. 
4. Berdasarkan data responden pada rentang usia 21-54 tahun berjuklah 20 orang mereka manyatakn bahwa kualitas baik dapat memuakan konsumen.

5. Karena dengan kualitas, mutu dan manfaat yang baik konsumen akan merasa puas ketika membeli buah apel nongkojajar.

\section{KESIMPULAN}

Berdasarkan hasil penelitian dan pembahasan maka terdapat kesimpulan sebagai berikut :

1. Faktor-fakyor yang mempengaruhi kepuasan konsumen adalah Harga (X1), dengan nilai Korelasi 0,367, (Alpha 0,735), Kualitas (X2) dengan nilai Korelasi 0,440, (Alpha 0,735),Rasa (X3) dengan nilai Korelasi 0,419, (Alpha 0,735), dan desain (X4) dengan nilai Korelasi 0,423, (Alpha 0,735).

2. Diantara atribut Apel Nongkojajar, variabel harga dan kualitas memiliki pengaruh nyata terhadap kepuasan konsumen apel nongkojajar yang lebih besar/dominan.

\section{DAFTAR PUSTAKA}

Arikunto, Suharsimi. 2002. Prosedur penelitian Suatu Pendekatan Ppraktek. Edisi Lima. Yogyakarta : Rineka Cipta.
Assuari, Sofyan. 2004. Manajemen

Pemasaran. Edisi Lima. Jakarta :

Penerbit Armico.

Cravens, David W. 1996. Pemasaran Strategi Adisi keempat. Jakarta : penerbit Erlangga.

Goleman. 2002. Ilmu Kepribadian. Cetakan kedua. Jakarta: Ghalia Indonesia.

Indrianti. 2010. Kepuasan Konsumen. Yogyakarta : Penerbit Erlangga.

Kotler, Philip. 1994. Marketing Management : Analisis, Planning, Implementation and Control. 8th Edition, prentice-Hall International.

Kotler, Philip. 1997. Manajemen Pemasaran: Analisis. Perencanaan Implementasi dan Pengendalian, Buku Satu, Salemba Empat Prenticel-Hall. Jakarta.

Kotler, Philip dan Gary Armstrong, 2000. Prinsip-prinsip Pemasaran. Jilid 1, Edisi Kedelapan. Jakarta. Erlangga.

Kotler, Philip dan Gary Armstrong, 2001. Prinsip-prinsip Pemasaran. Jilid 2, Edisi Kedelapan. Jakarta. Erlangga.

Kotler, Philip. 2002. Manajemen Pemasaran. Jilid 1. Jakarta: prinhallind.

Kotler, Philip dan Gary Armstrong, 2004. Dasar-dasar Pemasaran.jakarta: PT. Indeks.

Kotler, Philip. 2005. Manajemen Pemasaran. Jilid 2. Jakarta: PT. Indeks. 
Saladin, Djaslim. 2002. Manajemen

Pemasaran. Jakarta: Salemba

Empat.

Setiadi. 2003. Perilaku Konsumen.

Cetakan Pertama. Bandung :

Penerbit PT. Eresco.

Staton, William.1991. Kepuasan

Konsumen. Edisi Tujuh. Jakarta:

Erlangga.

Sugiyono. 2002. Metode Penelitian Bisnis.

Cetakan sembilan. Bandung:

Alfabeta.

Swastha, Basu dan Handoko, T. Hani.

2000. Manajemen Pemasaran,

Analisis Pengaruh Konsumen.

Edisi pertama. Yogyakarta :

Penerbit Liberty.

Schnaars. 2004. Perilaku Konsumen.

Catakan Keempat. Terjemahan

Mangkunegara. Bandung : Penerbit

PT. Eresco.

Tjiptono, Fandi. 2005. Strategi Pemasaran.

Cetakan Pertama. Yogyakarta:

Penerbit Andi Offset.

Tjiptono, Fandi. 2005. Strategi Pemasaran.

Cetakan kedua. Yogyakarta:

Penerbit Andi Offset.Tjiptono,

Fandi. 1997. Strategi Pemasaran.

Cetakan ketiga. Yogyakarta:

Penerbit Andi Offset. 